\section{Pollution from the Soviet Union}

\section{A.J. Southward}

Pollution and the Biological Resources of the Oceans.

By S. A. Patin.

Butterworth Scientific: 1983. Pp.289. $£ 35$, \$89.95.

THE industrial nations vary in the care they devote to protection and restoration of the marine environment, and a sort of pecking order has been informally recognized. Soviet Russia has generally been placed rather low in this ranking system, and the popular scientific press has carried stories about the destruction of natural communities in the Caspian Sea and Lake Baikal. It is therefore a pleasant surprise to encounter this updated translation of $\mathrm{Dr}$ Patin's book, which gives an account of Soviet investigations of marine pollution as part of a general review of the subject.

Dr Patin is a radiochemist who later moved into the field of experimental ecotoxicology of fish, and these two aspects are well-covered in the book. The introductory chapter describes the general background to pollution studies, and gives definitions of terms and concepts. It is worth noting the author's implied criticism of autecological investigations - concentration on one organism to the exclusion of the rest of the ecosystem - and of the dilution concept so often used to excuse discharges into the sea. Dr Patin states firmly that the toxic criteria for sea water should include changes in production and species composition, disappearance of sensitive species, alterations to biochemical pathways and disturbances to the ecological balance; he is clearly not one of those persons who regard the presence of any form of life, however restricted in diversity, as an indication that pollution is not harmful.

The next chapter describes patterns of world pollution, and an attempt is made to formulate a global model of epipelagic pollution. Attention is drawn to localization of pollution adjacent to industrial sources and to the concentration of many pollutants in a thin layer at the air-water interface. Chapter 3 tabulates occurrences of pollutants such as radiochemicals, oil, heavy metals and chlorinated hydrocarbons. The author then shows how these substances are distributed and accumulated in marine organisms, using both graphs and tables. His summary of the incidence of heavy metals and chlorinated hydrocarbons in commercial marine products is especially useful, in that it is accompanied by statistical parameters that show the degree of individual variation. It is made quite clear that heavy metal content increases in the general order oceanicneritic-inland sea; fish from the Caspian contain nearly twice as much mercury $(0.275 \mathrm{mg} / \mathrm{kg})$ in their muscles as do fish from the North and Barents Seas, which in turn contain twice as much as fish from the Atlantic Ocean.

Dr Patin then turns to methods of investigation - including a lucid explanation of toxic effect areas and permissible (reversible action) zones in three-dimensional plots - and reviews the experimental approach with unicellular algae in the laboratory and the field; he recommends monitoring changes in rate of photosynthesis as a more sensitive indicator than cell division.

The section on animals is arranged in systematic order, and among fishes it is interesting to see how sensitive to pollution are the eggs of sturgeon and some local forms of salmonids compared with typical test species such as cyprinids. Following two chapters summarizing general features in distribution of pollution and the biological consequences, the final chapter offers suggestions for control and monitoring. The author ends by stressing that the scientific and technological advances that have caused pollution could equally be employed in reducing the volumes of harmful substances emitted. $\mathrm{He}$ admits, however, that the search for such solutions and their full-scale realization will be expensive, and that there is little prospect of substantial reduction in marine pollution in the next decades.

This is a readable book, well-translated and produced apart from a few misprints and peculiar Russianizations of the names of Western researchers. Not only does it provide a good introduction to the whole subject of marine pollution, but also many valuable insights into otherwise inaccessible Soviet researches.

A.J. Southward is at the Marine Biological Association, Plymouth.

\section{Light on experiment}

\section{P.M. Rentzepis}

\section{Experimental Methods in Photochemistry and Photophysics.}

By J.F. Rabek.

Wiley: 1982. 2 volumes, pp.1,098.

£89.95, \$189.50.

THE SUBTITLE of these two books might well have been "An Encyclopaedia of Experimental Photochemistry"! Starting with the "Nature and Properties of Light" and "Optical Radiation Sources", Rabek proceeds to discuss in simple, coherent language the basic aspects and the instruments used in photochemistry and photobiology. From sunlight to picosecond lasers, Rabek makes a successful attempt to provide the photochemist with a working knowledge of instrument components, their designs and their modes of operation. Rather than engulfing the reader in theory and mathematics, the author describes in a straightforward fashion how and under what conditions each component operates efficiently in the laboratory.

Chapter 4 , which covers in about 70 pages the various lenses and prisms most commonly used by the photochemist, provides the bare minimum of background on the theoretical principles of optics. Such material is found in other texts but was usefully included here to inform the photochemist or photobiologist of component composition, characteristics and applications.

The way in which Rabek discusses and illustrates the various optical components reminds one, in some respects, of the descriptions to be found in manufacturers' catalogues. The accounts are nonetheless generally informative and provide the necessary insight for the construction of experiments, although in places the treat- ment is very elementary and will be of use only to neophytes.

The chapters on photodetectors, especially the one dealing with multichannel detectors, are especially timely and well written. They provide the essential information for the selection and operation of vidicons and optical multichannel analysers, instruments which are becoming essential in many spectroscopic experiments. Similarly, the chapter on signal recovery includes a list of the instruments available, for example oscilloscopes, lockin amplifiers, photon counters and optical multichannel analysers.

The second volume is mostly concerned with laser and fast spectroscopic measurement techniques, although there is a short description of electronic transitions which gives only definitions of terms. The chapter on emission spectroscopy is written for newcomers to the field rather than specialists, as indeed are all of the basic chapters in both books. There is, however, an extensive account of actinometry which is broad in scope and examines most of the actinometric and radiometric methods used by photochemists interested in absolute quantum yields. The treatise ends with a pertinent description of the more common hazards in photochemical research and the means for avoiding them.

These two books are well written, easily understood and encompass most of the necessary information for the practice of photochemical research. They are not texts on the theoretical principles of the subject, but rather an encyclopaedic compilation of instruments for photochemists and photobiologists. As such they provide a convenient and easily accessible source of information which is difficult to find elsewhere.

P.M. Rentzepis is Head of the Physical and Inorganic Chemistry Research Department at Bell Laboratories, Murray Hill, New Jersey. 